\title{
Broken rotor bar detection in LS-PMSMs based on statistical features analysis of start- up current envelope
}

\begin{abstract}
Early detection of asymmetry in electrical motors is important because of their diversity of use in different fields. A proper fault detection scheme helps to stop propagation of the failure or limit its escalation to severe degrees and thus prevents unscheduled downtimes that cause loss of production and financial income. Line start-permanent magnet motor (LS-PMSM) is one of the modern high efficiency motor introduced to the market recently. A new method for the fault diagnosis of a broken rotor bar in line-start permanent magnet synchronous motor is presented in this paper. The method is based on the analysis of the transient stator current envelopes of LS-PMSM using statistical features in time domain analysis. Four different level of load were investigated in this study to indicate the effect of load in broken rotor bar detection. Hilbert Transform is used to extract the envelope of the current signal during the transient reign.
\end{abstract}

Keyword: Broken rotor bar; Envelope signal; Fault detection; LS-PMSM; Statestical feature; Time domain; Transient current signal 